\title{
SOBRE MULHERES, ESCRITA E RESISTÊNCIA: DESAFIOS CONTEMPORÂNEOS'
}

\section{ON WOMEN, WRITING AND RESISTANCE: CONTEMPORARY CHALLENGES}

\section{Sandra Regina Goulart Almeida²}

RESUMO: O trabalho faz uma reflexão sobre a literatura produzida por mulheres e a crítica literária feminista ao longo dos anos e aborda os principais desafios a serem enfrentados no momento atual, procurando refletir sobre as formas possíveis de resistência articulada por meio da escrita.

Palavras-chave: mulheres, resistência, escrita, crítica literária feminista

ABSTRACT: This work proposes to discuss women's literature and feminist literary criticism over the past years and focuses on the major challenges to be faced at the moment, examining the possible forms of resistance articulate through writing.

Keywords: women, resistance, writing, feminist literary criticism

We die. That may be the meaning of life. But we do language. That may be the measure of our lives ${ }^{3}$

Toni Morrison

O cuidado de minha poesia Aprendi foi de mãe... insisto, foi ela

a fazer da palavra artifício

arte e ofício do meu canto de minha fala ${ }^{4}$

This is the power of the telling of a story ${ }^{5}$ Mohja Kahf

\footnotetext{
${ }^{1}$ Artigo recebido em 14 de agosto de 2019 e aceito para publicação em 02 de dezembro de 2019

2 Doutora pela Universidade da Carolina do Norte, Chapel Hill, Professora Titular de Estudos Literários da UFMG, pesquisadora em produtividade em pesquisa do CNPq, srga@ufmg.br.

3 "Nós morremos. Esse pode ser o sentido da vida. Mas nós fazemos a linguagem. Essa pode ser a medida das nossas vidas". Toni Morrison (1931-2019), Nobel de Literatura (1993), morreu em 5/8/19, aos 88 anos.

${ }^{4}$ Conceição Evaristo (1946-), poema "De mãe"

5 “Esse é o poder de contar histórias". Mohja Kahf (1967- ), poeta, escritora árabe-americana. Do poema "So you think you know Scheherazad?"
} 


\section{Preâmbulo}

Começo com uma nota pessoal. Sou professora da área de literatura de língua inglesa, literatura comparada, estudos feministas e de gênero, trabalho com mulheres na literatura há mais de 20 anos e estou, com muito orgulho, Reitora da UFMG, gestão 2018-2022. Tenho dito também que não escolhemos o momento de servir a nossa Instituição, somos escolhidos por nossas comunidades para cumprir uma missão, a mais honrosa e, com certeza, a mais difícil das tarefas a nós delegadas. E neste momento posso dizer que é a tarefa mais difícil já enfrentada por reitores/as nos últimos 50 anos da vida de nossas instituições. Digo isto porque descobri, tentando escrever este texto, que não há como dissociar a professor/pesquisadora da gestora/reitora. Meu lugar de fala - para usar um tempo recorrente e atual dos estudos feministas e culturais o qual retomarei ao fim deste texto - é hoje esse espaço duplamente marcado.

Este trabalho que trata das mulheres, da escrita e da resistência como desafios contemporâneos é dividido em 5 partes: I. Preâmbulo, II. O poder da linguagem, da escrita e da literatura, III. desafios contemporâneos, IV. narrativas de resistência, V. lugar de fala.

Minha proposta neste artigo é pensar a literatura como nosso objeto de estudo, mas também como nossa mestra, nossa meta em busca da reflexão acerca tanto do "humano" - evocado já em nossa filiação à área de Ciências Humanas, conforme mencionado por Spivak em Death of a Discipline? - quanto do "pós-humano", sobre o qual nos fala também Donna Haraway em seu influente estudo sobre o ciborgue da década de 90.

Começo com o poder da linguagem e da escrita.

\section{0 poder da linguagem e da escrita}

Início com a citação de 3 escritoras, que escolhi para abrir esta fala e que nos ajudam a pensar: a) o poder da linguagem e da escrita; b) os desafios contemporâneos, c) narrativas de resistência, tanto no campo da literatura quanto em nossas experiências do presente.

Em primeiro me refiro à uma citação conhecida de Toni Morrison, escritora Afro-Americana, falecida em 5 de agosto último: "Nós morremos. Esse pode ser o sentido da vida. Mas nós trabalhamos a linguagem. Essa pode ser a medida das nossas vidas". Para Morrison trabalhar a linguagem nos permitir uma intervenção, argumento que vemos frequentemente em 
seus trabalhos, capaz de influenciar e guiar nosso modo de vida. A linguagem nos permite construir percepções da realidade que nos moldam como seres humanos e como pensadoras críticas que somos.

De maneira semelhante, Conceição Evaristo, em seu renomado poema "De mãe" afirma que: "O cuidado de minha poesia/Aprendi foi de mãe.../ insisto, foi ela/ a fazer da palavra/ artifício/ arte e ofício/ do meu canto/ de minha fala". No poema citado acima, Conceição Evaristo fala da herança e do aprendizado da escrita e da palavra por meio da mãe, cujo legado permeia sua experiência de vida. A escrita, o uso das palavras, o poema é uma herança materna, uma arte, um ofício, um artifício, um trabalho com um fim, um propósito, uma inspiração. Fazer da palavra sua fala requer uma ação e um protagonismo aprendido pelo contato materno.

No poema, "So You Think you Know Scheherazad?" [Então você acha que conhece Sherazade?] publicado na coletânea de poemas E-mails from Scheherazad, a escritora Mohja Kahf, nascida na Síria e hoje residente nos Estados Unidos, resgata por meio da imagem mítica de Sherazade a função da mulher e narradora que detém o poder de criar mundos alternativos, mudar o curso da estória e o controle de agenciar seu destino. Na verdade, como a voz poética nos informa, Sherazade não inventa nada, simplesmente acorda os demônios escondidos nos mais recônditos espaços lacunares e transporta o ouvinte/leitor para outros mundos imaginados. Esse é o poder da narração de uma estória, o poder de desvendar narrativas e "soltar demônios" (KAHF, 2003, p. 44), de criar por meio da escrita um "espaço de contestação", sobre o qual nos fala Arjun Appadurai (APPADURAI, 1996, p. 4).

No poema que dá título à coletânea, "E-mails From Scherezade", Kahf descreve uma Sherazade do século 21 que conta com fina ironia seu retorno ao novo milênio para ganhar a vida (ambiguamente para não perdêla) contando estórias: "Eu Ihe conto estórias para ganhar a vida./ Você me pergunta se esse é um meio de vida./ Você precisa se lembrar: de onde eu venho/ Pode-se morrer pelas palavras" (2003, p. 43, minha tradução). ${ }^{6}$ E, assim, o poder liberado ("Powers unleashed") que brota dessa aventura com as palavras - pelas quais se anseiam, mas pelas quais também se morre (presente na ambiguidade do termo "die for") - desencadeia uma teia

6 "I tell stories for a living/ You ask if there is a living in that. / You must remember: Where I come from,/ Words are to die for". 
narrativa espiralada e infinita. É sobre o poder da linguagem, das palavras e da escrita e das narrativas - o poder de contar estórias evocado por Morisson, Evaristo e Kahf - que permeia essas três citações que convido todas a refletir sobre a literatura - nosso objeto de estudo e nossa mestra sobre nossa. Essas três citações nos permitem pensar sobre o papel e impacto da literatura, especialmente quando fazemos uma reflexão sobre as mulheres e a escrita.

Primeiramente, a capacidade de "fundar reinos", criar narrativas por meio da linguagem, como diria Adélia Prado. Se partirmos do pressuposto de que a literatura é uma prática cultural que trabalha não apenas com a representação por meio da linguagem e do discurso, mas também com a construção, produção ou mesmo a desconstrução de nossas percepções do mundo ao nosso redor, ${ }^{7}$ como postulam claramente várias teóricas feministas, como Teresa de Lauretis (1987), Pam Morris (1993), Nelly Richard (2002) e Rita Felski (2003), Susana Funck, e tantas outras, a literatura contemporânea nos fornece subsídios para refletirmos sobre este conturbado momento histórico do presente de mudanças geopolíticas intensas, de acirramento de posições, de intolerância e medo, mas também de uma presença histórica das mulheres em todas as esferas da sociedade, em geral, e da literatura, em especial.

Como postula Beatriz Sarlo, crítica argentina, a "literatura, é claro, não dissolve todos os problemas colocados, nem pode explicá-los, mas nela um narrador sempre pensa de fora da experiência, como se os humanos pudessem se apoderar do pesadelo, e não apenas sofrê-lo" (SARLO, 2007, p. 119). É precisamente a partir de uma experiência de fora que pretende se "apoderar do pesadelo" que podemos pensar o papel das escritoras contemporâneas que observam, analisam e questionam seu tempo, frequentemente balizada pelas questões de gênero, deixando transparecer de forma contundente os efeitos dos fenômenos atuais nas relações humanas e entre homens e mulheres.

\footnotetext{
7 É importante ressaltar também o sentido duplo do termo representação, como observa Spivak em "Pode o subalterno falar". Partindo do sentido dos dois termos em alemão (Vertretung e Darstellung) que acabaram por ser incorporados no mesmo termo tanto em inglês quanto em português, Spivak argumenta que o primeiro termo, que conota um sentido político de falar pelo outro, se opõe e, ao mesmo tempo, complementa o segundo, que se refere ao ato de encenação ou performance. Estamos aqui diante do sentido estético do termo, "o conceito filosófico da representação como encenação ou, de fato, significação", "sua cena de escrita" (SPIVAK, 2010, p. 41-43). 
Vejam o que diz Gayatri Spivak em Quem pode cantar a nação:

\begin{abstract}
Uma das coisas que [Simon] Gikandi ${ }^{8}$ diz é que o genocídio geralmente se baseia em narrativas.... $\mathrm{Na}$ oralidade, ele diz, é possível mostrar que nas próprias narrativas há momentos que traem a versão genocida, mas são as pessoas nessa suposta configuração que precisam assumir uma parte ativa no reconhecimento do potencial mitopoético ativo da narrativa histórica, não apenas citando Heródoto, mas também assumindo isso como uma tarefa prática por devir. Uma noção mitopoética de história é aquela em que a história está no processo de devir. $\mathrm{E}$ então me parece que podemos de fato pensar na história como mitopoética em termos de prática política e não apenas especulação filosófica. (2018, p. 98)
\end{abstract}

Tanto Sarlo quanto Spivak aborda uma questão crucial para nossa reflexão, tanto com relação à literatura quanto ao momento que vivemos que diz respeito ao papel/poder das narrativas na construção de uma dada realidade e de um campo de disputa. Enquanto Sarlo fala da potencialidade das narrativas para "se apoderar do pesadelo", Spival, a partir de Gikandi, fala da narrativa histórica, da "história como mitopoética em termos de prática política".

O segundo ponto, diz respeito ao papel da literatura na aproximação com o outro. A possibilidade do movimento em direção ao encontro com o outro marca o literário como um espaço dialógico (no sentido bakhtiniano) tanto pela interação com o outro quanto pela demarcação da literatura como espaço de representações e produções culturais. Para citar uma colocação de Compagnon, podemos, então, indagar como podemos pensar a literatura - no nosso horizonte a literatura produzida por mulheres na contemporaneidade - como um espaço de "formação de si mesmo", bem como o "caminho em direção ao outro" (COMPAGNON, 2009, p. 54). "É possível existir vida sem o outro", para citar uma coletânea de artigos publicados pela Fundação Gulbenkian, em Portugal? (Can there be life without the Other? 2009). Para o argentino Ricardo Piglia, em "Uma proposta para o novo milênio", a sexta proposta não escrita por Calvino seria justamente esse encontro com o outro:

\footnotetext{
${ }^{8}$ Simon Gikandi é um escritor e crítico literário, especialista em literatura queniana e literatura pós-colonial. É professor da Universidade de Princeton. 


\begin{abstract}
A verdade tem a estrutura de uma ficção em que outro fala. Fazer na linguagem um lugar para que $o$ outro possa falar. A literatura seria o lugar em que é sempre outro quem vem dizer. "Eu sou outro", como dizia Rimbaud. Sempre há outro aí. Esse outro é o que se deve saber ouvir para que aquilo que se conta não seja mera informação, mas tenha a forma da experiência. Creio, então, que poderíamos imaginar que há uma sexta proposta. A proposta que eu chamaria, então, de distância, deslocamento, mudança de lugar. Sair do centro, deixar que a linguagem fale também na margem, no que se ouve, no que chega de outro.
\end{abstract}

Falar, pois, do poder da linguagem, da escrita e da literatura pressupõe em minha análise essas duas questões centrais: a) capacidade de construção de mundos; b) movimento em direção ao outro.

\title{
Desafios contemporâneos
}

Não poderia deixar de destacar algumas questões que, como pesquisadora da área, têm perpassado o campo da literatura escrita por mulheres e da crítica literária feminista.

No romance $A$ distância entre nós (2005), a escritora indiana radicada nos Estados Unidos, Thrity Umrigar, constrói uma narrativa instigante e intricada que tem como pano de fundo a Índia contemporânea, uma cidade cosmopolita, sectária e excludente como tantas outras nos países em desenvolvimento. Narra a história de vida de duas mulheres indianas - Bhima e Sera - de classes sociais diferentes que compartilham uma vivência perpassada pelas inerentes contradições do mundo em que vivem. Separadas pelo rígido sistema social, econômico e cultural da sociedade indiana, essas mulheres se unem em torno de problemas comuns às mulheres indianas - ambas sofrem discriminação e exploração sexual. No entanto, essas mulheres são oprimidas de formas diferentes pela própria constituição de classes que as separa. Há entre Sera e Bhima uma hierarquia que confere à última um espaço ainda mais relegado no sistema excludente da sociedade contemporânea. Se Sera passou a vida toda sofrendo abusos físicos e psicológicos de seu marido, sendo espancada com frequência, Bhima é forçada a lidar com um outro tipo de abuso, resultante de sua posição inferior na escala social. Sua neta, Maya, a quem reservava 
um futuro melhor do que o de outras mulheres de sua família, ao entrar para a universidade, se vê grávida, após ter sido estuprada pelo genro de Sera. Esse episódio marca de forma contundente a enorme distância entre as personagens femininas, pois acaba por conferir a Maya o destino de tantas mulheres de sua classe social: a exploração sexual e uma vida de sujeição e subordinação. Confrontada com a realidade crua, a sempre solícita, compreensiva e afável Sera é incapaz de transpor as barreiras de classe que a separam de Bhima para pensar naquilo que as une, optando por preservar a cegueira que Umrigar parece condenar na classe média alta indiana. Sera se torna, assim, cúmplice do aniquilamento final de Bhima, acusada injustamente de roubo pelo genro de Sera. Se, por um lado, o romance termina com a liberação simbólica de Bhima, às margens do mar da Arábia, quando essa percebe que, de certa forma, é livre e sujeito de seu próprio destino; por outro lado, aponta para a impossibilidade de reparação dos males dessa mulher pobre e destituída. Ninguém pode falar por Bhima, nem ela mesma. Quando tenta falar, não é ouvida - o dilema da mulher subalterna que Spivak expõe tão bem em termos teóricos em "Pode o subalterno falar?". No final, apesar do aparente otimismo de Bhima, o leitor sabe que a ela não resta mais nada. Sem trabalho, sem esperanças para o futuro da neta, sem condições de garantir o sustento próprio e o de Maya, a única ligação tênue que lhe prende à vida é a dignidade de saber que não Ihe resta mais nada a fazer, já que nenhuma forma de agenciamento será capaz de lhe proporcionar os meios de uma vida honrada, que ela sabe que Ihe pertence de direito, como cidadã de um mundo cosmopolita, porém desigual e nefasto.

Esse romance nos alerta tanto para o que nós mulheres temos em comum quanto para o que nos diferencia e ainda para o que nos distância. Por isso, é extremamente importante falarmos sobre "mulheres"sempre no plural destacando a diversidade e a diferença entre nós, mas também sobre o que temos em comum e o que pode ser instrumento de luta em defesa de questões que compartilhamos como mulheres. Há, no entanto, toda uma dinâmica relacional de poder - que inclui diferenças significativas de classe, raça e etnia, sexualidade, idade, áreas do conhecimento - à qual não podemos estar alheias. Não podemos falar pelas muitas mulheres que hoje são silenciadas. Não podemos clamar por uma suposta irmandade e igualdade quando sabemos que umas são menos 
iguais do que outras, como nos lembra também George Orwell. Assim, precisamos abrir caminho para que outras mulheres possam falar por si, para que elas possam se manifestar sobre suas experiências sobre as quais nós muitas vezes desconhecemos ou mesmo ignoramos.

\section{A falácia da diferença sexual}

Ficarmos apegadas a diferenças entre homens e mulheres não nos leva a lugar algum. É claro que não podemos ignorar que há diferenças biológicas entre os sexos, mas não podemos tratá-los como aspectos determinantes. Como diria Simone de Beauvoir: "não se nasce uma mulher, se torna uma mulher" - ou seja não é o determinismo biológico que constrói a imagem das mulheres, mas sim uma construção social e cultural que diz o que devemos ser ou como devemos nos comportar e que opera por meio de uma rede de estereótipos, muitas vezes cruéis, colocando em cena um jogo que conjuga, como lembra Martha Nussbaum, a diferença corpórea e a construção cultural. Cito Chimamanda Adiche, escritora nigeriana, autora de dois livros cuja leitura recomendo: Sejamos todos feministas e Para educar crianças feministas: "O problema da questão de gênero é que ela descreve como devemos ser em vez de reconhecer como somos. Seríamos bem mais felizes, mais livres para sermos quem realmente somos, se não tivéssemos o peso das expectativas de gênero."

Nesse sentido, pode-se pensar em alguns desafios que se colocam hoje para se pensar em um diálogo profícuo entre literatura e crítica feminista. Um deles, apropriadamente delineado por Rita Schmidt, seria a dificuldade da travessia da fronteira entre as categorias conceituais do "campo discursivo do feminismo para categorias de análise" da "crítica literária e de seu objeto de estudo que é o texto literário" (Schmidt, 2010, p. 269). O desafio seria pensar o literário como um campo privilegiado de inserção dos estudos feministas e como um espaço de articulação e contestação de narrativas que ainda insistem em se posicionar como hegemônicas. Como a literatura produzida por mulheres se coloca diante da de um discurso reacionário gerado por uma percepção despolitizante de agenciamento feminino (Shirin Ray, 2008), isto é, um discurso de agenciamento que privilegia as batalhas supostamente já vencidas, a liberdade e a escolha das mulheres, encobrindo perigosamente os vários problemas ainda enfrentados pelas mulheres em outros contextos e em 
várias partes do mundo. Penso principalmente na relação da literatura com o que se denominou chamar de feminismo popular ou pós-feminismo (nas palavras de Ângela McRobbie $^{9}$ ) e de um vetor da literatura que tem ganhado espaço na mídia contemporânea - o que se convencionou chamar de "chick-lit" ou "literatura de mulherzinha". Ou ainda na distância entre nossas teorizações como feministas e as experiências e vivências de tantas mulheres com quem nos deparamos diariamente, bem como nas representações midiáticas e literárias.

Como podemos nos afastar de um discurso vitimizante que, como nos mostra bell hooks, nos reduz à passividade, e pensar em estratégias e narrativas de resistência que possam ser libertadoras, em sintonia com o que Chantal Mouffle denomina de "modalidades de resistência estética"?

\section{Narrativas de resistência}

Rita Felski, em um texto apropriadamente intitulado Literature after Feminism, destaca como "a literatura é uma das linguagens culturais através da qual fazemos sentido do mundo" em que vivemos, sendo um campo "saturado de significados sociais", mas ao mesmo tempo em que "nos ajuda a criar nosso sentido de realidade ao invés de simplesmente refleti-la". O feminismo "tem influenciado nossa visão dos textos literários" e é importante destacar como, "esses textos, por sua vez, dialogam de volta com o feminismo" (2003, p. 13), fomentando assim um sistema crítico que desloca posicionamentos e coloca em crise modelos epistemológicos (e ontológicos) tradicionais.

A crítica feminista, cuja teorização partiu significativamente dos estudos literários, mudou nosso sentido do que é considerado literatura, desmantelando a oposição modernista entre estética e política e oferecendo a possibilidade de uma "dupla visão", isto é, de se poder analisar conjuntamente a arte e o social, o estético e o político (FELSKI, 2003, p. 21). Para Richard, o "cruzamento de fronteiras entre teoria, estética e política", que caracteriza as diferentes vozes da crítica feminista hoje, garante uma articulação produtivamente desestabilizadora (RICHARD, 2002, p. 166-168)

\footnotetext{
${ }^{9}$ Refiro-me aqui ao argumento de McRobbie de que "post-feminism positively draws on and invokes feminism as that which can be taken into account, to suggest that equality is achieved, in order to install a whole repertoire of new meanings which emphasize that it is no longer needed, it is spent force" (2004, p.255).
} 
que nos permite imaginar o poder e o alcance dessa produção cada vez mais abundante e multifária. Assim, como lembra Rita Schmidt,

é indispensável acreditar que as energias feministas no campo dos estudos literários têm a potencialidade de interferir no discurso crítico, revitalizar o ensino e fecundar uma agenda educativo-pedagógica-política capaz de interromper as continuidades históricas das exclusões, da violência e do preconceito. Essa interrupção implica a desestabilização das estruturas patriarcais, a transgressão de paradigmas binários, vigentes no campo social e no campo científico, a descolonização do pensamento em sentido amplo e irrestrito e a reinvenção de subjetividades. (SCHMIDT, 2010 , p. 270, grifos meus)

É justamente essa possibilidade de pensar o trabalho teórico como uma forma de interrupção - mencionado por Schmidt e teorizado também por Stuart Hall como o trabalho teórico como forma de interrupção -, questionando posicionamentos e interrompendo um fluxo crítico outrora contínuo, que tem levado a uma ruptura produtiva no estudo da cultura como aquela efetuada pelos estudos feministas, de gênero e pelos estudos sobre etnicidade e raça (HALL, 1996) por meio de escritas e narrativas de resistência.

Assim, pode-se dizer que é a crítica feminista que força uma interrupção teórica e epistemológica, que "ao soltar os demônios", sobre os quais nos fala Kahf, apodera-se da palavra, narrativizando os construtos imaginários e se apossando da escrita como forma de desestabilizar o poder instituído e de refletir sobre questões de poder, vitimização e agenciamento. Narrativas de resistência como essas tornam visíveis, por um lado, um processo de vitimização histórica e o legado de silenciamento e invisibilidade; por outro, almejam evidenciar um agenciamento necessário, sem contudo ser laudatório ou negar as condições existenciais e materiais de uma grande parcela da população, aí incluídas as mulheres como uma categoria complexa, multifária, contingenciada pelos múltiplos constituintes identitários e a existência inequívoca de "hierarquias de gênero, classe e raça" (EAGLETON, 2005, p. 5) .

É importante também considerar como essas narrativas de resistência podem ser compreendidas tanto como um efeito quanto um afeto (no sentido que Spinoza dá ao termo: de se sentir afetado por algo 
que nos leva a agir), que se traduz numa relação política, mas também em uma reação emocional para com o mundo contemporâneo como tal (AHMED, 2003, p. 238) - o que Rosi Braidotti denomina apropriadamente de "feminismo transformativo". Tal feminismo deveria, a meu ver, pressupor uma pedagogia crítica que pode ser concebida em termos do que Spivak denomina de "letramento transnacional" que viria a se contrapor aos movimentos globais da atualidade por meio de um aprendizado crítico de leitura dos discursos da contemporaneidade, assegurando um fazer crítico que "decolonize" o pensamento. Isso somente seria possível por meio de uma pedagogia crítica na qual pudéssemos "desaprender" nossos privilégios, procurando "pensar de maneira diferente, aprendendo a produzir teoria em outros espaços "por meio de um hábito literário de ler o mundo" para "reivindicar o papel do ensino da literatura como um treinamento da imaginação" (2003, p. 13). Tal conceito parece instrumental no sentido de que uma das formas mais produtivas de propiciar uma leitura crítica dos discursos da atualidade é por intermédio de textos literários e de discursos de escritores e escritoras que contestam e problematizam o atual cenário atual, não apenas pela representação, mas também pela construção e produção de uma percepção de mundo, unindo tanto o estético quanto o político e promovendo a dupla reflexão proporcionada pela literatura, sobre a qual nos fala Felski e Richard.

Assim, um dos desafios que se coloca hoje para a crítica literária feminista seria, ${ }^{10}$ a meu ver, o de pensar o literário como um campo privilegiado de inserção dos estudos feministas e como um espaço de articulação e contestação de narrativas provendo o que Maria Lugones destaca como um pensamento decolonial que coloque em xeque a construção do gênero na modernidade.

Podemos, então, indagar que reflexões teóricas são suscitadas pelas escritas de autoras contemporâneas? Como se dá o diálogo entre as críticas literárias feministas e a literatura produzida por escritoras contemporâneas? Como essas produções literárias podem ser vistas como um campo privilegiado de inserção dos estudos feministas e como um espaço de articulação e contestação de narrativas hegemônicas? Como o

\footnotetext{
10 Um outro desafio apropriadamente delineado por Rita Schmidt seria a travessia da fronteira entre as categorias conceituais do feminismo e o campo discursivo da crítica literária (SCHMIDT, 2010, p. 269).
} 
afeto atua nessas narrativas de resistência? Como se aproximar, ouvir e abrir espaço para o outro/a? Qual capacidade de intervenção e resistência pode ter uma narrativa que evoque um pensamento decolonial? Como se apoderar do pesadelo?

\section{Lugar de fala}

A UFMG tem 90 anos, mas sou apenas a 3 a mulher a ocupar este posto. Isso diz muito sobre a dinâmica das relações de gênero na Academia. Não é menos significativo que as Reitoras - e mentoras - que me antecederam, Profas. Vanessa Guimarães e Ana Lúcia Gazzola, eram da área das Ciências Humanas. Se hoje mais de $50 \%$ das estudantes que entram na Universidade são mulheres, elas não estão, como sabemos igualmente distribuídas pelas áreas de conhecimento. É notória a ausência das mulheres nas áreas de ciências exatas, assim como é de conhecimento de todos e todas que à medida que alçamos a pirâmide acadêmica em cargos de destaque, o número de mulheres diminui consideravelmente.

Com essas mulheres de fibra, com quem compartilho da satisfação de "cumprir a sina, inaugurar linhagens, fundar reinos", como diria a poeta Adélia Prado, minha mais generosa acolhida e meu mais profundo respeito. Repito o que disse em meu discurso de posse: "que sirvamos de modelo e exemplo a tantas jovens e tantas mulheres na necessária luta por emancipação, liberdade e igualdade de condições, e contra o preconceito que ainda vítima tantas de nós".

O tempo atual é carregado de contradição. Se, por um lado, vivemos momento de incerteza e retrocessos na agenda de demandas das mulheres, por outro lado, nunca estivemos diante de um fenômeno em que tantas mulheres se identificam com a pauta em defesa dos direitos das mulheres e da igualdade de gênero. Trabalho na área desde o início da década de 90, quando fui muitas vezes "acusada" de ser feminista e trazer para o Brasil um modelo importado dos EUA que não se adequava à índole carinhosa e descontraída do brasileiro.

Acredito que temos que representar uma aposta na direção contrária: a aposta no diálogo, na reflexão crítica e na resistência. Como diria a escritora Eliane Brum, precisamos "resistir ao medo e se juntar para criar futuro é o ato primeiro de resistência". "É preciso voltar a encarnar as palavras", diria Brum, as palavras de Toni Morrison, de Conceição Evaristo, 
de Mohja Kahff, de Adélia Prado, de Thrity Umrigar e de tantas outras escritoras. É preciso também criar o comum, o que nos une. Vivemos momentos nos quais deve sobressair, a elaboração de estratégias para resistir a um ataque sistemático- que operam no campo material e prático, do estrangulamento de políticas públicas para as mulheres e no campo simbólico de disputa de narrativas, de tentar minar o a legitimidade de nossas lutas. A criação comum começa pela aproximação com o outro/a e pela linguagem, como nos lembra Brum. É uma luta antiga que precisamos todas abraçar hoje mais do que nunca. Que Emily Dickinson nos sirva de inspirar em um de seus mais potentes versos: "A esperança tem asas. / Faz a alma voar. / Canta a melodia sem saber a letra. / E nunca desiste. Nunca".

\section{Referências}

AHMED, S. Feminist Futures. In: EAGLETON, M. A Concise Companion to Feminist Theory. London: Blackwell, 2003. p. 236-254.

APPADURAI, A. Modernity at Large: Critical Dimensions of Globalization. Minneapolis, London: University of Minnesota Press, 1996.

COMPAGNON, A. Literatura para quê? Trad. Lauda Taddei Brandini. Belo Horizonte: Editora UFMG, 2009.

DERRIDA, J.; DUFOURMANTELLE, Anne. Da hospitalidade. Anne Dufourmantelle convida Derrida a falar da hospitalidade. Tradução de Antonio Romane. São Paulo: Escuta, 2003.

FELSKI, R. Literature after Feminism. Chicago and London: The University of Chicago Press, 2003.

FRIEDMAN, S. S. Mappings: Feminism and the Cultural Geographies of Encounter. Princeton: Princeton University Press, 1998.

HALL, S. Cultural Studies and Its Theoretical Legacies. In: MORLEY, D.; CHEN, K. (Eds.). Stuart Hall Critical Dialogues in Cultural Studies. London: Routledge, 1996. p. 262-275.

KAHF, M. E-mails form Scheherazad. Gainesville: University Press of Florida, 2003.

KRISTEVA, J. Strangers to Ourserlves. Trans. Leon S. Roudiez. New York: Columbia University Press, 1991.

LAURETIS, T. de. Technologies of Gender: Essays on Theory, Film, and Fiction. Bloomington and Indianopolis: Indiana University Press, 1987. 
Sandra Regina Goulart Almeida

RICHARD, N. Intervenções críticas: arte, cultura, gênero e política. Belo Horizonte. Editora UFMG, 2002.

SARLO, Bz. Tempo Passado: cultura da memória e guinada subjetiva. Trad. Rosa Freire de Aguiar. São Paulo/Belo Horizonte: Companhia das Letras/UFMG, 2007.

SCHMIDT, R. T. Revisitando a mulher na literatura: horizontes e desafios. 2010.

SPIVAK, G. C. Claiming Transformation: Travel Notes with Pictures. In: AHMED, S.; KILBY, J.; LURY, C.; MACNEIL, M.; SKEGGS, B. Transformations: Thinking Through Feminism. London and New York: Routledge, 2000. p. 119130 .

SPIVAK, G. C. Death of a Discipline. New York: Columbia University Press, 2003.

SPIVAK, G. C. Pode o subalterno falar? Trads. Sandra Regina Goulart Almeida, Marcos Pereira Feitosa, André Pereira Feitosa. Belo Horizonte: Editora UFMG, 2010.

TY, E. The Politics of the Visible in Asian North American Narratives. Toronto: University of Toronto Press, 2004. 